\title{
La necesidad de transparencia en los casos de gobernanza de la cultura
}

\author{
Eréndira Sarahí Pérez Ponce | Máster en Dirección y Gestión Pública
}

URL de la contribución <www.iaph.es/revistaph/index.php/revistaph/article/view/3803>

Los enfoques y teorías con los cuales se ha pretendido explicar la realidad y relaciones entre actores en materia de política cultural devienen de postulados de los campos de las ciencias sociales principalmente, siendo el de gobernanza el de más impacto y con mayor adopción en los últimos tiempos (PRATS, 2005). Paradigmas en crisis como las administraciones weberianas, postulados postburocráticos y de la nueva gestión pública abonan la promoción de dicho término, donde sociedad civil, mercado, globalización, colaboración, organización, participación, recursos escasos y rendición de cuentas encuentran un campo epistémico ad hoc para explicar sinergias innovadoras o hasta antes no visibilizadas.

En particular, gobernanza cultural (SCHMITT, 2011), de la cultura (WEBER, 2010), de las artes o patrimonial invita a la reflexión de la acción pública en estos ámbitos, reconociendo que el brazo gubernamental resulta insuficiente para lograr objetivos específicos y que requiere de la participación de otros actores, ya sean sociales y/o económicos. Incluso autores como Maynzt (2005) defienden la tesis de que, para denominarse gobernanza, estos sectores actuarán sin la dirección de un órgano oficial o con una participación mínima de este, generalmente delimitado a la observancia y promulgación de las leyes.

Aunque un análisis profuso respecto al nivel de participación por parte del gobierno en la cultura no es menester del presente, es preciso señalar que en Estados como los iberoamericanos, la potestad sobre el patrimonio está legislada para que los gobiernos sean quienes lo protejan, administren y conserven, por lo cual se encuentra un primer límite a la participación de agentes extragubernamentales. Este hecho, añadido a sociedades en las cuales el factor asociativo es débil, desemboca en prácticas verticales del poder, donde los outputs o productos provienen de la caja negra de sistema político (EASTON, 1969) en forma de planes, programas o proyectos gubernamentales en esta materia.

No obstante, frente a la insuficiencia de recursos (económicos, humanos, materiales) para la atención total y cabal de todas las necesidades de protección, restauración, catalogación, promoción, conservación y mantenimiento de los bienes culturales de cada nación, otros actores han alzado la mano para la actuación en ello y en diferente intensidad, que van desde la autogestión, el crowdfunding, el mecenazgo (MUÑOZ, 2015), el adherirse a una estrategia comunitaria o incluso haciendo un llamamiento a la exigencia de intervención (o no), hasta llegar a la existencia de conflictos sociales.

Este baremo de participación es el punto nodal de la reflexión del presente, pues en los procesos de colaboración pública-privada-social, no todos los actores realizan este acercamiento en la misma medida, en los mismos términos, ni para los mismos fines. Dentro del espectro público no gubernamental se abordan dos grandes esferas: la económica y la social. Y aunque no están tan limitadas como se pensaría, Bauman dixit, coinciden en estar organizadas en torno a una idea, y en función de ello, tener capacidad de inclusión o influencia en la agenda pública del patrimonio.

Lógicamente las organizaciones de corte económico tienen un origen empresarial y una finalidad de rentabilidad: ¿quién, si no, está invirtiendo en la cultura actualmente? En ellas se abre un abanico de categorías como el mercado del arte, las fundaciones (las bancarias desde el Renacimiento y en su máxima expresión durante las últimas dos décadas), las asociaciones de la industria cultural (editoriales, escritores, cineastas, restauradores) y empresas artísticas, productoras, consultoras, turísticas, 
de diverso tamaño, entre muchas más. Asimismo, las organizaciones sociales, con un público objetivo y aparentemente no lucrativo. Entre ellas se encuentran las organizaciones no gubernamentales, las asociaciones civiles, grupos vecinales, sectores sociales, escolares, gremiales o académicos.

Ambos tipos, en general, son colectivos que están interesados en la participación por la sencilla razón de tener una relación directa con la afectación o beneficio de una acción u omisión pública. Naturalmente, la gobernanza cultural reconoce que cada actor tendrá intereses e injerencias específicas. No obstante, habría que cuidar los límites de ello, pues el beneficio público debería primar sobre el resto. Además, que una decisión tomada exclusivamente por un sector podría generar corrupción o desigualdad de condiciones (de participación, de beneficio, de derechos, etcétera).

Por ejemplo, si se diera una libertad total respecto a la restauración de todo el patrimonio por particulares, ¿quién garantiza que experiencias como la del Ecce Homo de Borja (Zaragoza) no se repetirán? ¿Cómo se obliga a la no apropiación de patrimonio para beneficio únicamente privado (incluyendo algunas administraciones públicas)? ¿Dónde están los limites de responsabilidad o esta sólo se aplica al sector gubernamental? ¿Se primará el derecho a la cultura sobre la capacidad de acceso a ella?

La evidencia empírica resultante de los trabajos de investigación en esta materia muestra que la participación proveniente de la esfera privada o de las organizaciones no gubernamentales en el ámbito cultural público presentan productos y casos diferenciados para estos cuestionamientos, por lo que no podemos juzgar a priori los resultados de cada caso. Pues en algunos de ellos también localizamos elementos importantes de análisis como la creatividad, la solidaridad, el liderazgo, la confianza, la cooperación, la autogestión y la creación de redes público-privadas/gubernamentales-sociales, no como agentes enfrentados sino como complementarios; es decir, de gobernanza cultural.
Visualizar y visibilizar estas relaciones entre actores, intereses y acuerdos heterogéneos resulta en suma complejo, pero exigible a razón de la naturaleza del tema: el patrimonio cultural es un recurso eminentemente público. Por lo cual podríamos referirnos a casos exitosos de colaboración siempre y cuando no se trate de intereses contrarios a los generales. Entonces, propiciar la generación de transparencia y rendición de cuentas en estos procesos de colaboración no solamente daría creación de valor público al patrimonio cultural sino que ante actuaría como input y output de confianza y legitimidad en la sociedad.

\section{BIBLIOGRAFÍA}

- EASTON, D. (1969) Esquema para el análisis político. Buenos Aires: Ed. Amorrortu, 1969

- MAYNZT, R. (2005) Nuevos desafíos de la teoría de Governance. En CERRILLO I MARTíNEZ, A. (coord.) La gobernanza hoy: 10 textos de referencia. Madrid: Instituto Nacional de Administración Pública, 2005

- MUÑOZ, S. (2015). El patrimonio cultural y su mantenimiento en tiempos de crisis. Patrocinio, mecenazgo y crowdfunding: ¿La solución? revista $P H,{ }^{\circ}{ }^{\circ} 87$, abril, 2015, pp. 5-7

- PRATS, J. (2005) De la Burocracia al Management, del Management a la Gobernanza. Las transformaciones de las Administraciones públicas de nuestro tiempo. Madrid: Instituto Nacional de Administración Pública, 2005

- SCHMITT, T. (2011) Cultural Governance as a conceptual framework. MMG Working Paper, 11-02 <http://www.mmg. mpg.de/fileadmin/user_upload/documents/wp/WP_11-02_ Schmitt_Cultural-Governance.pdf> [consulta: 15/07/2016]

- WEBER, R. (2010) Quelle gouvernance pour la culture et le secteur culturel? Document de travail pour le campus euroaméricain de Las Palmas de Gran Canaria (30 novembre-3 décembre 2010) 